\title{
Impaired anti-inflammatory function of apolipoprotein A-II concentrations predicts metabolic syndrome and diabetes at 4 years follow-up in elderly Turks
}

\author{
Altan Onat 1,2,*, Gülay Hergenç3 ${ }^{3}$ Erkan Ayhan4, \\ Murat Uğur ${ }^{4}$ and Günay Can² \\ ${ }^{1}$ Turkish Society of Cardiology, Istanbul, Turkey \\ ${ }^{2}$ Departments of Cardiology and Public Health, \\ Cerrahpasa Medical Faculty, Istanbul University, \\ Istanbul, Turkey \\ ${ }^{3}$ Department of Biology, Yildiz Technical University, \\ Istanbul, Turkey \\ ${ }^{4}$ Department of Cardiology, Siyami Ersek \\ Cardiovascular Disease Center, Istanbul, Turkey
}

\begin{abstract}
Background: We evaluated prospectively the predictive value of serum apolipoprotein (apo) A-II, the second major apolipoprotein of high-density lipoprotein (HDL), for cardiometabolic risk in Turkish adults showing abnormalities in other proteins that normally confer protection.

Methods: Determinants of apoA-II and its associations with coronary heart disease (CHD), metabolic syndrome (MetS) and diabetes were investigated at 4 years follow-up in 193 elderly men and women.

Results: ApoA-II concentrations at baseline, in addition to being significantly related to HDL-cholesterol, were directly associated with complement C3 in multivariate linear regression analyses comprising nine variables. Following adjustment for gender, age and $\mathrm{HDL}$-cholesterol (>30/>33 $\mathrm{g} / \mathrm{L}$, in men and women, respectively), low serum apoA-II concentrations predicted incident MetS [relative risk (RR) 3.5 (95\% Cl 1.4; 8.6)] and type 2 diabetes [RR $4.5(95 \% \mathrm{Cl} 1.3 ; 15.6)]$ in both genders at an increment of 1 SD. Increased apoA-II values were not associated with prevalent or incident $\mathrm{CHD}$, and tended to be marginally atheroprotective only in males.

Conclusions: Serum apoA-II concentrations confer risk for MetS and diabetes and exhibit evidence of anti-inflammatory properties among Turks. These findings support the effects seen for several other HDL protein constituents. This finding may explain the increased cardiometabolic risk among Turks.

Clin Chem Lab Med 2009;47:1389-94.
\end{abstract}

Keywords: apolipoprotein A-II; coronary heart disease; diabetes; metabolic syndrome; proinflammatory state.

* Corresponding author: Prof. Dr. Altan Onat, Nisbetiye cad. 59/24, Etiler 34335, İstanbul, Turkey

Phone: +90 212351 6217, Fax: +90 212351 4235,

E-mail: alt_onat@yahoo.com.tr

Received June 18, 2009; accepted July 24, 2009;

previously published online October 12, 2009

\section{Introduction}

Apolipoprotein (apo) A-II is the second most common protein constituent of high-density lipoprotein (HDL), comprising $20 \%$ of the HDL protein (1). Studies in apoA-II transgenic mice indicate that apoA-II regulates the metabolism of triglyceride-rich lipoproteins (TRL), being transferred to TRLs from the HDL protein stores (2). In apoA-II transgenic mice, human apoA-II is reabsorbed in kidney proximal tubules in relation to its plasma concentration, and then degraded (3). In animals expressing human apoA-Il carried by very low-density lipoprotein (LDL), the association of human apoA-II with TRL induces postprandial hypertriglyceridemia due to inhibition of lipoprotein lipase and hepatic lipase activities (4).

ApoA-Il has been suggested in some studies to have poor antiatherogenic or even proatherogenic properties $(5,6)$. High lipoprotein A-I (LpA-I), but not LpA-I/A-II concentrations, were associated with a more favorable metabolic risk profile in the HERITAGE Family study (7). In patients with coronary artery disease, apoA-II concentrations were found to be low-normal (8) or high (in interstitial fluid) (9) in different studies. But apoA-II was shown in a recent prospective, large nested case-control analysis, the EPIC-Norfolk study, to be associated with a decreased risk of coronary disease $(\mathrm{OR}=0.48$ upper vs. lowest quartile, $95 \% \mathrm{Cl} 0.34 ; 0.67)$ in apparently healthy subjects. This finding implied that there are effects from apoA-II on specific antiatherogenic pathways (10). The authors believed that arguments for a potential proatherogenic effect of apoA-II were no longer valid. Apparent cardioprotection was shown by APOAll rs5082 polymorphism in another case-control analysis of nearly 1000 Australian men (11): the CC genotype exhibited lower risk of coronary artery disease $(\mathrm{OR}=0.57, \mathrm{p}=0.004)$ compared with $\mathrm{T}$ allele carriers.

The question of whether apoA-Il concentrations in humans are involved in protecting against risk of metabolic disorders has not been adequately investigated $(12,13)$. In a previous cross-sectional analysis of an elderly sample from the Turkish Adult Risk Factor (TARF) study, using logistic regression analyses, gender- and age-adjusted apoA-II concentrations were not shown to be associated with coronary heart disease (CHD), metabolic syndrome (MetS) or type 2 diabetes (14). However, recent prospective analyses in the TARF showed that increased serum apo A-I was diabetogenic and tended to be atherogenic among Turks (15). In addition, increased concentrations of adiponectin (16), HDL-cholesterol (17) and apoC-III in HDL (18) showed similar effects. The abnormal func- 
tions of these normally protective serum proteins have been proposed to result from an environment of atherogenic dyslipidemia, excessive oxidative stress and systemic low-grade inflammation associated with the high prevalence of MetS among Turks (19).

Our goal was to investigate whether apoA-II is contributory to the prediction of development of MetS, diabetes and CHD in males and females using followup data from a sample population. In the event of a pro-inflammatory effect, the independence of this association from that of HDL-cholesterol levels, demonstrated in the TARF study (17), was investigated.

\section{Subjects and methods}

\section{Subjects}

Due to economic constraints, the study sample consisted of randomly selected elderly participants of the TARF study (20). Selection was based primarily on age and those likely to be at high cardiometabolic risk. The study sample consisted of individuals reported previously in a cross-sectional study of serum apoA-II (measured in 2003) (14). Participants were $35-80$ years of age at baseline and were residents from regions of Central Anatolia and Marmara. The study was approved by the Ethics Committee of the Istanbul University Medical Faculty. Written informed consent was obtained from all participants.

Waist circumference was measured midway between the lower rib margin and the iliac crest with the subject standing at the end of expiration. Cigarette smoking status was categorized into current smokers, former smokers and those that never smoked. Individuals taking alcohol once a month or more were considered to be users of alcohol. Blood pressure was measured in the sitting position using the right arm with an aneroid sphygmomanometer (Erka, Bad Tölz, Germany), after at least $5 \mathrm{~min}$ of rest. The mean of two recordings, taken $3 \mathrm{~min}$ apart, was used. Physical activity was graded into one of four categories (20). Lipid lowering drugs were used by six participants, hormone replacement therapy in three.

Blood samples were collected following $11 \mathrm{~h}$ or more of fasting in $91 \%$ of individuals. Samples were shipped on cooled gel packs to Istanbul to be stored at $-75^{\circ} \mathrm{C}$, until anal$y$ sis at the Yıldız Technical University. Serum concentrations of apoA-II, A-I and B, complement $\mathrm{C} 3$ and $\mathrm{C}$-reactive protein (CRP) were measured using nephelometry (BN Prospec, Behring Diagnostics, Westwood, MA, USA). The intraassay CV for apoA-II with both was $1.4 \%$ and the interassay CV was $5.5 \%$. Serum concentrations of total cholesterol, fasting triglycerides, glucose, and HDL-cholesterol (directly without precipitation) were determined by using enzymatic kits from Roche Diagnostics with a Hitachi 902 autoanalyzer (Roche Diagnostics, Mannheim, Germany). Serum phospholipid measurements were performed colorimetrically with WAKO's phospholipids B kits. Insulin concentrations were determined by the chemiluminescent immunometric method using reagents from Roche and the Elecsys 1010 immunoanalyzer.

\section{Definitions and outcomes}

Diabetes was diagnosed using criteria of the American Diabetes Association (21), a fasting plasma glucose $\geq 7.0$ $\mathrm{mmol} / \mathrm{L}$ (or 2-h postprandial glucose $>11.1 \mathrm{mmol} / \mathrm{L}$ ) and/or the current use of diabetes medication. Individuals with MetS were identified when three of five criteria of the
National Cholesterol Education Program (ATP III) (22) were met, modified for prediabetes (fasting glucose 5.56$6.99 \mathrm{mmol} / \mathrm{L}(23)$ and further for abdominal obesity using as cut point $\geq 95 \mathrm{~cm}$ in men, as recently assessed in the TARF study (24).

Diagnosis of non-fatal CHD was based on the presence of angina pectoris, a history of myocardial infarction with or without accompanying Minnesota codes of the ECG (25), or on a history of myocardial revascularization. Typical angina and, in women, an age $>45$ years was a prerequisite for diagnosis when angina was isolated. ECG changes of "ischemic type" of greater than minor degree (Codes 1.1-2, 4.1-2, $5.1-2,7.1)$ were considered as myocardial infarct sequelae or myocardial ischemia. CHD death comprised fatal coronary event and death from heart failure of coronary origin.

Exclusion and follow-up Of the 102 men and 91 women comprising the sample, patients with prevalent CHD, MetS and diabetes were excluded in the analysis of respective incident outcomes. Participants were monitored for 4 years, from 2003 when apoA-Il was measured until 2007.

\section{Data analysis}

Descriptive parameters were evaluated as means \pm standard deviation (SD) or percentages. Two-sided t-tests and Pearson's $\chi^{2}$-tests were used to analyze the differences in means and proportions between groups. Pearson correlations were used for continuous and Spearman correlations for categorical or log-transformed variables. Linear regression analysis was performed with apoA-II as the dependent variable. Estimates (and 95\% confidence intervals) for relative risk (RR) of a dependent variable were determined by use of logistic regression analyses in models that controlled for gender, age and serum HDL-cholesterol. With respect to CHD risk, confounders, such as smoking status, alcohol use and lipid lowering drugs were included. ApoA-Il concentrations were divided into gender-specific high (in rounded figures $>0.30$ / $>0.33 \mathrm{~g} / \mathrm{L}$ in men and women, respectively) and low apoAII concentrations. The cut-off threshold represented the 47th percentile in each sex. RRs were expressed in terms of increments of $1 \mathrm{SD}$ of apoA-II $(0.061 \mathrm{~g} / \mathrm{L})$, or other variables. The gradient across high and low mean apoA-II values corresponded to $1.3 \mathrm{SD}$. This value was used as the exponent to calculate and express the RRs in terms of 1 SD increment. A value of $p<0.05$ on the two-sided test was considered statistically significant. Statistical analyses were performed using SPSS-10 for Windows (SPSS Inc., Chicago, IL, USA, Nr. 9026510).

\section{Results}

At baseline, MetS was present in 85 (56\%), diabetes in $36(19 \%)$ and CHD in $51(26 \%)$ patients. Total followup consisted of 637 (mean 3.30) person-years during which 18 incident CHD, 25 MetS and 13 type 2 cases of diabetes developed.

Clinical characteristics of the sample population (mean age $63 \pm 10$ years) at baseline are shown in Table 1, according to gender. Participants were generally (abdominally) obese; women exhibited a tendency for hypertension, increased concentrations of LDL-cholesterol, fasting triglycerides, complement C3 and fibrinogen. These tendencies in females have been observed, albeit to a lesser extent, in the entire TARF cohort. Several variables were measured on a 
Table 1 Baseline characteristics of the study sample $(n=193)$.

\begin{tabular}{|c|c|c|c|c|c|c|}
\hline & \multicolumn{3}{|l|}{ Men } & \multicolumn{3}{|c|}{ Women } \\
\hline & $\mathrm{n}$ & Mean & SD & $\mathrm{n}$ & Mean & SD \\
\hline ApoA-II, g/L & 102 & 0.304 & 0.04 & 91 & 0.337 & 0.07 \\
\hline Age, years & 102 & 63.4 & 11.2 & 91 & 62.8 & 9.4 \\
\hline Waist circumference, cm & 102 & 97.9 & 12.7 & 91 & 96.7 & 11.2 \\
\hline Body mass index, kg/m² & 102 & 28.4 & 4.9 & 91 & 31.9 & 5.6 \\
\hline Systolic blood pressure, mmHg & 102 & 137.0 & 19.4 & 91 & 143.9 & 20.4 \\
\hline Diastolic blood pressure, $\mathrm{mmHg}$ & 103 & 84.1 & 10.9 & 91 & 85.6 & 9.4 \\
\hline Total cholesterol, mmol/L & 102 & 4.89 & 0.92 & 91 & 5.79 & 1.09 \\
\hline HDL-cholesterol, mmol/L & 102 & 1.02 & 0.27 & 91 & 1.26 & 0.39 \\
\hline LDL-cholesterol, mmol/L & 91 & 3.05 & 0.79 & 91 & 3.67 & 0.88 \\
\hline Fasting triglycerides, $\mathrm{mmol} / \mathrm{L}$ & 91 & 1.75 & 0.96 & 84 & 1.88 & 0.88 \\
\hline Total phospholipids, mg/dL & 44 & 188.4 & 34.9 & 39 & 216.3 & 33.3 \\
\hline Fasting glucose, mmol/L & 83 & 5.8 & 1.97 & 75 & 5.9 & 2.25 \\
\hline Fasting insulin ${ }^{\mathrm{a}}, \mathrm{mIU} / \mathrm{L}$ & 75 & 7.94 & 1.8 & 77 & 9.11 & 1.7 \\
\hline Apolipoprotein A-I, g/L & 79 & 1.30 & 0.20 & 70 & 1.54 & 0.29 \\
\hline Apolipoprotein B, g/L & 55 & 1.12 & 0.31 & 60 & 1.29 & 0.56 \\
\hline Complement C3, g/L & 59 & 1.29 & 0.26 & 64 & 1.39 & 0.24 \\
\hline C-reactive protein ${ }^{a}, \mathrm{mg} / \mathrm{L}$ & 99 & 2.3 & 3.6 & 85 & 3.1 & 2.8 \\
\hline Uric acid, mmol/L & 70 & 345 & 71 & 60 & 298 & 95 \\
\hline Current/former smokers, n \% & 102 & $35 / 39$ & $34 / 37$ & 91 & $11 / 4$ & $12.1 / 4.4$ \\
\hline Alcohol use, \% & 102 & 12.6 & & 91 & 0 & \\
\hline
\end{tabular}

aLog-transformed values.

subset of participants, but logistic regression analyses were not significantly affected by these limitations.

\section{Relationship of apoA-II with other risk parameters}

Correlation between apoA-II and selected parameters are shown in Table 2. The strongest correlation $(r$ 0.34-0.63) was seen with serum phospholipids, apoA-I, HDL- and total cholesterol, complement C3 and triglycerides. This was much weaker in women. Male age showed an inverse correlation.

Linear regression models for each gender using covariates of apoA-II comprising nine variables considered to be related to a pro-inflammatory state lage, smoking status, alcohol use, level of physical activity, waist circumference, systolic blood pressure, and log CRP, complement C3 and HDL-cholesterol) explained the high apoA-Il variance in men. In contrast, the model as a whole did not significantly explain the apoA-II variance in women $(p=0.26)$. HDLcholesterol was significantly associated with apoA-II in both genders, but only age and complement C3 showed significant association in men (Table 3).

Results of logistic regression analyses of high ( $>0.30 />0.33 \mathrm{~g} / \mathrm{L})$ vs. low apoA-II concentrations for incident MetS or type 2 diabetes are given in Table 4. After adjustment for gender, age and HDL-cholesterol, a $1 \mathrm{SD}$-increment in apoA-II values predicted MetS significantly in both males and females with an RR of $3.5(95 \% \mathrm{Cl} 1.4 ; 8.6)$. Diabetes was also predicted by high apoA-Il concentrations, showing RR of 4.5 (95\% Cl $1.3 ; 15.6)$ at an increment of 1 SD. RRs in either gender, although higher in females, did not attain significance due to the low number of events.

Table 5 shows the logistic regression analyses of high vs. low apoA-II concentrations for incident CHD or for an endpoint of combined prevalent and incident CHD, after adjustments for gender, age, HDL-choles-

Table 2 Correlations of serum apoA-II with risk parameters, by gender.

\begin{tabular}{|c|c|c|c|c|c|c|}
\hline & \multicolumn{3}{|c|}{ Men $n=102$} & \multicolumn{3}{|c|}{ Women $\mathrm{n}=91$} \\
\hline & $\mathrm{n}$ & $r$ & $\mathrm{p}$-Value & $\mathrm{n}$ & $r$ & $\mathrm{p}$-Value \\
\hline Phospholipids ${ }^{\mathrm{a}}, \mathrm{mg} / \mathrm{dL}$ & 43 & 0.63 & $<0.001$ & 39 & 0.60 & $<0.001$ \\
\hline ApoA-I ${ }^{a}, g / L$ & 79 & 0.30 & 0.008 & 70 & 0.19 & 0.12 \\
\hline HDL-cholesterol, mmol/L & 102 & 0.38 & $<0.001$ & 91 & 0.29 & 0.005 \\
\hline Total cholesterol, $\mathrm{mmol} / \mathrm{L}$ & 102 & 0.42 & $<0.001$ & 91 & 0.10 & 0.36 \\
\hline Complement C3, g/L & 58 & 0.36 & 0.005 & 66 & 0.16 & 0.21 \\
\hline Triglycerides ${ }^{a}, \mathrm{mmol} / \mathrm{L}$ & 91 & 0.34 & $<0.001$ & 84 & 0.04 & 0.71 \\
\hline LDL-cholesterol, mmol/L & 100 & 0.24 & 0.017 & 86 & -0.01 & 0.93 \\
\hline Body mass index ${ }^{a}, \mathrm{~kg} / \mathrm{m}^{2}$ & 102 & 0.15 & 0.14 & 91 & -0.03 & 0.81 \\
\hline Smoking status ${ }^{\mathrm{a}}$ & 102 & -0.08 & 0.42 & 91 & -0.10 & 0.34 \\
\hline Age $^{a}$, years & 102 & -0.25 & 0.012 & 91 & -0.06 & 0.58 \\
\hline Uric acid, mmol/L & 70 & 0.15 & 0.21 & 60 & -0.20 & 0.13 \\
\hline Fasting glucose ${ }^{\mathrm{a}}, \mathrm{mmol} / \mathrm{L}$ & 83 & 0.13 & 0.23 & 75 & 0.03 & 0.78 \\
\hline Fasting insulin ${ }^{\mathrm{b}}, \mathrm{mlU} / \mathrm{L}$ & 74 & 0.13 & 0.26 & 77 & -0.11 & 0.36 \\
\hline C-reactive protein ${ }^{\mathrm{b}}, \mathrm{mg} / \mathrm{L}$ & 98 & -0.07 & 0.49 & 85 & -0.06 & 0.58 \\
\hline
\end{tabular}

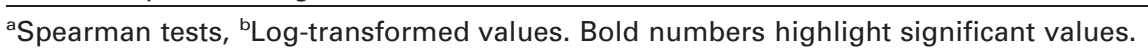


Table 3 Multivariable linear regression for covariates of serum apoA-II, by gender $(n=116)$.

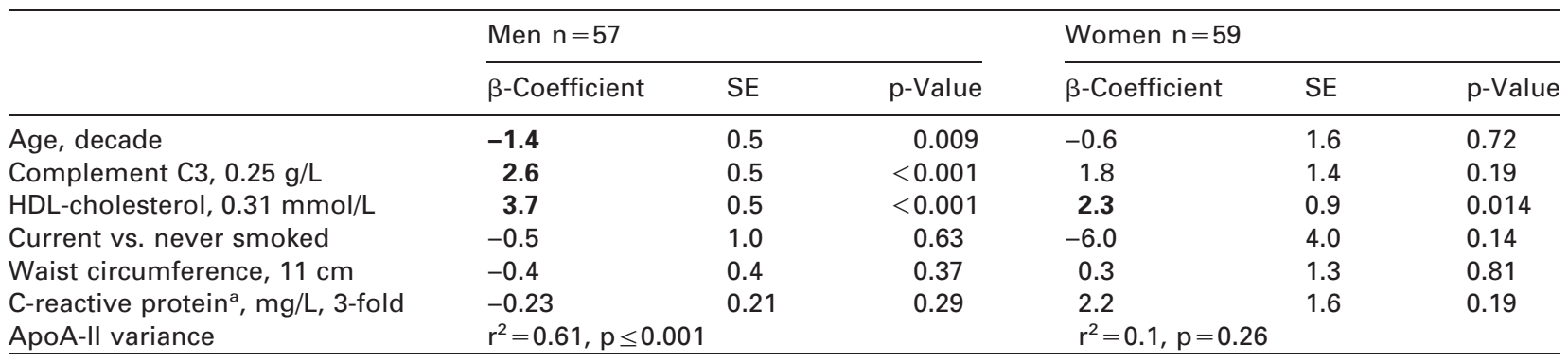

a Log-transformed. Model adjusted also for systolic blood pressure, physical activity grade, alcohol use (all $p>0.3$ ). Bold numbers highlight significant values.

Table 4 Logistic regression analysis of high vs. low apoA-II concentrations for incident metabolic syndrome (MetS) and type 2 diabetes.

\begin{tabular}{|c|c|c|c|c|c|c|}
\hline \multirow[b]{2}{*}{ Incident MetS } & $\underline{\mathrm{RR}}$ & $95 \% \mathrm{Cl}$ & $\underline{\mathrm{RR}}$ & $95 \% \mathrm{Cl}$ & $\underline{\mathrm{RR}}$ & $95 \% \mathrm{Cl}$ \\
\hline & \multicolumn{2}{|c|}{ Total, $\mathrm{n}=25 / 85^{\mathrm{c}}$} & \multicolumn{2}{|c|}{ Men, $n=16 / 56$} & \multicolumn{2}{|c|}{ Women, $n=9 / 29$} \\
\hline Gender, female & 1.89 & $0.52 ; 6.88$ & & & & \\
\hline Age, 5 years & 1.09 & $0.86 ; 1.38$ & 0.93 & $0.67 ; 1.23$ & 1.95 & $1.02 ; 3.76$ \\
\hline ApoA-II, >0.30/>0.33 g/L vs. Iow & 3.5 & $1.4 ; 8.6$ & 2.8 & $0.91 ; 8.6$ & 9.8 & $0.87 ; 111$ \\
\hline $\mathrm{HDL}$ cholesterol $^{\mathrm{b}}, 0.31 \mathrm{mmol} / \mathrm{L}$ & 0.51 & $0.27 ; 0.95$ & 0.37 & $0.12 ; 1.14$ & 0.49 & $0.19 ; 1.27$ \\
\hline Incident diabetes & \multicolumn{2}{|c|}{ Total, $n=13 / 157^{c}$} & \multicolumn{2}{|c|}{ Men, $n=9 / 82$} & \multicolumn{2}{|c|}{ Women, $n=4 / 75$} \\
\hline Gender, female & 0.96 & $0.24 ; 3.9$ & & & & \\
\hline Age, 5 years & 0.88 & $0.66 ; 1.18$ & 0.80 & $0.57 ; 1.14$ & 0.94 & $0.54 ; 1.63$ \\
\hline ApoA-II, $>0.30 />0.33$ g/L vs. Iow ${ }^{a}$ & 4.5 & $1.3 ; 15.6$ & 2.09 & $0.59 ; 7.45$ & 3.6 & $0.55 ; 23.6$ \\
\hline HDL-cholesterol $^{\mathrm{b}}, 0.31 \mathrm{mmol} / \mathrm{L}$ & 0.42 & $0.17 ; 1.06$ & 0.56 & $0.17 ; 1.86$ & 0.39 & $0.10 ; 1.56$ \\
\hline
\end{tabular}

${ }^{a}$ Expressed in terms of $1 \mathrm{SD}$ increment in apoA-II, bhas to be inversely related to MetS by selection according to definition, ${ }^{c}$ number of new events/number at risk in model. Bold numbers highlight significant values.

Table 5 Logistic regression analysis of multi-adjusted high vs. low apoA-Il concentrations for prevalent and incident coronary heart disease (CHD).

\begin{tabular}{|c|c|c|c|c|c|c|}
\hline & $\underline{\mathrm{RR}}$ & $95 \% \mathrm{Cl}$ & $\underline{\mathrm{RR}}$ & $95 \% \mathrm{Cl}$ & $\underline{\mathrm{RR}}$ & $95 \% \mathrm{Cl}$ \\
\hline Incident CHD & \multicolumn{2}{|c|}{ Total, $\mathrm{n}=18 / 142^{\mathrm{b}}$} & \multicolumn{2}{|c|}{ Men, $n=12 / 74$} & \multicolumn{2}{|c|}{ Women, $\mathrm{n}=6 / 68$} \\
\hline ApoA-II, $>0.30 />0.33 \mathrm{~g} / \mathrm{L}^{\mathrm{a}}$ & 0.68 & $0.29 ; 1.63$ & 0.57 & $0.10 ; 3.14$ & 1.12 & $0.27 ; 4.68$ \\
\hline HDL-cholesterol, $0.31 \mathrm{mmol} / \mathrm{L}$ & 0.49 & $0.23 ; 1.09$ & 0.49 & $0.18 ; 1.41$ & 0.43 & $0.12 ; 1.49$ \\
\hline Prevalent and incident CHD & \multicolumn{2}{|c|}{ Total, $\mathrm{n}=67 / 191^{\mathrm{b}}$} & \multicolumn{2}{|c|}{ Men, $n=39 / 101$} & \multicolumn{2}{|c|}{ Women, $\mathrm{n}=29 / 91$} \\
\hline ApoA-II, $>0.30 />0.33 \mathrm{~g} / \mathrm{L}^{\mathrm{a}}$ & 0.94 & $0.53 ; 1.65$ & 0.74 & $0.31 ; 1.82$ & 1.07 & $0.48 ; 2.37$ \\
\hline HDL-cholesterol, $0.31 \mathrm{mmol} / \mathrm{L}$ & 0.70 & $0.48 ; 1.02$ & 0.69 & $0.36 ; 1.28$ & 0.69 & $0.44 ; 1.13$ \\
\hline Current vs. never smoked & 0.60 & $0.23 ; 1.56$ & 0.92 & $0.29 ; 2.91$ & 0.57 & $0.05 ; 6.20$ \\
\hline
\end{tabular}

Adjusted also for age and lipid lowering drugs (both $p<0.05$ ), gender and alcohol usage (both $p>0.05$ ). ${ }^{\text {a Expressed in terms }}$ of 1 SD increment in apoA-II, bnumber of new events/number at risk in model. Values in italic font type denote borderline significance.

terol, smoking status, alcohol use and lipid lowering drugs. RRs for high apoA-II were below unity [RR 0.74 $(95 \% \mathrm{Cl} 0.31 ; 1.82)]$ in men, but above unity in women [RR $1.07(95 \% \mathrm{Cl} 0.48 ; 2.37)]$ for a $1 \mathrm{SD}$ increment, without approaching significance. Findings appeared to be similar in the analyses for incident CHD.

\section{Discussion}

The present prospective study on an elderly Turkish adult population showed evidence of anti-inflammatory abnormalities associated with serum apoA-II concentrations. These results confirmed similar abnormal function for serum HDL and its other protein constituents (apoA-I and apoC-III) in a large number of Turks. After adjustments for HDL-cholesterol and other con- founders, high serum apoA-II concentrations predicted MetS and diabetes in all individuals compared with low apoA-II concentrations, implicating pro-inflammatory activity of this protein. However, high serum apoA-II tended to be marginally protective against CHD in men.

Comparative age-specific data on apoA-II concentrations are scarce. Values averaged $0.32( \pm 0.007$ SEM) $\mathrm{g} / \mathrm{L}$ in middle-aged Mexican-Americans (26), similar to those in the current study. Values were substantially higher in the PROCAM study, ranging between $39.5-41.9$ and $43.0-45.0 \mathrm{mg} / \mathrm{dL}$ in $15-64-$ year-old men and women, respectively (27).

It must be considered that most participants had abdominal obesity, with combined hyperlipidemia, hypertension, and usually with increased concentrations of acute phase reactants, such as complement 
C3 and fibrinogen, particularly in women. ApoA-II has been linked to combined hyperlipidemia. Ribas et al. (28) studied the ability of HDL to protect against oxidative modification of apoB-containing lipoproteins in mice. They found that incubation of isolated human apoA-Il with mouse control plasma decreased paraoxonase activity and displaced the enzyme from $\mathrm{HDL}$; thus overexpression of human apoA-II in mice impaired the normally protective ability of this protein.

\section{Manifestations of impaired anti-inflammatory/ anti-oxidative activities of apoA-II}

At odds with the anticipated positive anti-inflammatory activities of apoA-II particles, our population showed evidence for impaired anti-inflammatory activity. This was observed in baseline apoA-II concentrations with several variables representing enhanced systemic inflammation, such as correlation with body mass index, serum triglycerides, LDL-cholesterol, apoA-I [demonstrated to possess adverse properties $(15,17)]$ and being linearly related to complement C3. The finding of weaker correlations in females compared with males may be related to proinflammatory/pro-oxidant state having greater impact on cardiometabolic risk in Turkish women. Consequently, inflammation-related factors do not show significant independence. In addition, the development of MetS and diabetes was predicted by apoA-II concentrations, irrespective of HDL-cholesterol concentrations. This phenomenon is consistent with previously demonstrated cardiometabolic risk conferred by similar functional alterations in HDL (17), apoA-I (15), apoC-III in HDL (18) and in adiponectin (29) in the TARF cohort.

In transgenic mice, the human APOAll gene was stimulated by high carbohydrate intake following fasting. In mice that overexpressed this gene, plasma apoA-II concentrations were positively correlated with blood glucose concentrations. It was hypothesized that, in type 2 diabetes, increased apoA-II causes an increase in plasma triglycerides and glucose intolerance. This results in hyperglycemia, which in turn might increase APOA/l gene transcription (30).

Analyses showed that HDL cholesterol concentrations helped protect against the outcomes of diabetes and $\mathrm{CHD}$. This suggests that, when controlled for apoA-II, HDL particles largely retained both antiinflammatory and anti-atherogenic activities. It is considered that a pro-inflammatory state/oxidative stress, closely linked to the highly prevalent MetS in this population sample, is the main reason for an impaired protective function of apoA-II (and other proteins) by involvement of specific enzymes. Increased CHD risk in South Asian immigrants have been ascribed to similar HDL dysfunction involving its apolipoproteins (31).

Our findings are consistent with a view that separate apos on HDL may display specific dysfunction, which may be associated with impairment of reverse cholesterol transport of HDL particles. It appears that impaired apoA-II function is commonly associated with an increase in apoA-II concentrations. This might be related to reduced catabolism of apoA-Il which has been observed following the use of torcetrapib (32).

Limitations of the study include the small sample size, thus requiring caution in interpreting our findings until confirmed in other studies. However, the study sample allowed us to elicit the significant relationships with other inflammatory markers and development of MetS and diabetes. These observations are consistent with previous findings regarding other cardioprotective proteins. The applicability of the present findings to populations with a much lower prevalence of MetS and diabetes remains to be studied. The prospective design and the inclusion of both male and female subjects are strengths of the study.

\section{Conclusions}

High serum apoA-II concentrations do not protect, but rather predict the development of MetS and type 2 diabetes in Turks. It can be inferred that apolipoproteins may have inherent proinflammatory activities, presumably in populations with a high prevalence of MetS. These findings contribute to excess cardiometabolic risk among Turks.

\section{Conflict of interest}

None declared by the authors.

\section{Acknowledgements}

We thank the Turkish Society of Cardiology and the Pfizer, Novartis, Menarini-Ulagay and Schering-Plough companies (Istanbul) for partial financial support. We appreciate the dedicated works of Dr. Z. Küçükdurmaz, Dr. S. Bulur and Mr. M. Özmay, the coworkers in the survey teams.

\section{References}

1. Stein O, Stein Y. Atheroprotective mechanisms of HDL. Atherosclerosis 1999;144:285-301.

2. Castellani LW, Nguyen CN, Charugundla $S$, Weinstein MM, Doan CX, Blaner WS, et al. Apolipoprotein A-II is a regulator very low-density lipoprotein metabolism and insulin resistance. J Biol Chem 2008;283:11633-44.

3. Dugué-Pujol S, Rousset X, Chateau D, Pastier D, Klein C, Demeurie J, et al. Apolipoprotein A-II is catabolized in the kidney as a function of its plasma concentration. J Lipid Res 2007;48:2151-61.

4. Dugué-Pujol S, Rousset X, Pastier D, Quang NT, Pautre V, Chambaz J, et al. Human apolipoprotein A-II associates with triglyceride-rich lipoproteins in plasma and impairs their catabolism. J Lipid Res 2006;47:2631-9.

5. Blanco-Vaca F, Escola-Gil JC, Martin-Campos JM, Julve J. Role of apo A-II in lipid metabolism and atherosclerosis: advances in the study of an enigmatic protein. J Lipid Res 2001;42:1727-39.

6. Fournier N, Cogny A, Atger V, Pastier D, Goudouneche D, Nicoletti A, et al. Opposite effects of plasma from human apolipoprotein A-II transgenic mice on cholesterol efflux 
from J774 macrophages and Fu5AH hepatoma cells. Arterioscl Throm Vas 2002;22:638-43.

7. Couillard C, Bergeron J, Després JP, Gagnon J, Rankinen $\mathrm{T}$, Leon AS, et al. Apolipoprotein Al- and Al: All-containing lipoproteins in white men and women of the HERITAGE Family study: associations with metabolic risk profile variables. Metabolism 2003;52:160-6.

8. O'Brien T, Nguyen TT, Hallaway BJ, Hodge D, Bailey K, Holmes $D$, et al. The role of lipoprotein A-I and lipoprotein A-I/A-II in predicting coronary artery disease. Arterioscl Throm Vas 1995;15:228-31.

9. Luc G, Majd Z, Poulain P, Elkhalil L, Fruchart JC. Interstitial fluid apolipoprotein A-II: an association with the occurrence of myocardial infarction. Atherosclerosis 1996;127:131-7.

10. Birjmohun RS, Dallinga-Thie GM, Kuivenhoven JA, Stroes ES, Otvos JD, Wareham MJ, et al. Apolipoprotein A-II is inversely associated with risk of future coronary artery disease. Circulation 2007;116:2029-35.

11. Xiao J, Zhang F, Wiltshire S, Hung J, Jennens M, Beilby $\mathrm{JP}$, et al. The apolipoprotein All rs5082 variant is associated with reduced risk of coronary artery disease in an Australian male population. Atherosclerosis 2008;199: 333-9.

12. Elbein SC, Chu W, Ren Q, Wang H, Hemphill C, Hasstedt SJ. Evaluation of apolipoprotein A-II as a positional candidate gene for familial type II diabetes, altered lipid concentrations, and insulin resistance. Diabetologia 2002;45: 1026-33.

13. Castellani LW, Goto AM, Lusis AJ. Studies with apolipoprotein All transgenic mice indicate a role for HDLs in adiposity and insulin resistance. Diabetes 2001;50: 643-51.

14. Hergenç G, Onat A, Sansoy V, Türkmen S, Sarı I, Uzunlar $B$, et al. Apolipoprotein A-II levels and risk of coronary disease, metabolic syndrome and diabetes in a group of Turkish adults: a pilot study [abstract in English]. Arch Turk Soc Cardiol 2004;32:215-22.

15. Onat A, Hergenç G, Bulur S, Uğur M, Küçükdurmaz Z, Can G. The paradox of high apolipoprotein A-I levels independently predicting incident type-2 diabetes among Turks. Int J Cardiol 2009 (Jan 24 Epub) doi: 10.1016/j.ijcard.2008.12.066.

16. Onat A, Hergenç G, Can G, Küçükdurmaz Z. Serum adiponectin confers little protection against diabetes and hypertension in Turkish men. Obesity 2009;17:564-70.

17. Onat A, Can G, Ayhan E, Kaya Z, Hergenç G. Impaired protection against diabetes and coronary disease by high-density lipoproteins in Turks. Metabolism 2009 doi:10.1016/j.metabol.2009.05.004.

18. Onat A, Hergenç G, Ayhan E, Uğur M, Kaya H, Tuncer M, Can G. Serum apolipoprotein C-III in high-density lipoprotein: a key diabetogenic risk factor among Turks. Diabet Med 2009;26. doi: 10.1111/j.1464-5491.2009.02814.x.

19. Onat A, Ceyhan K, Başar Ö, Erer B, Toprak S, Sansoy V. Metabolic syndrome: major impact on coronary risk in a population with low cholesterol levels - a prospective and cross-sectional evaluation. Atherosclerosis 2002; 165:285-92.
20. Onat A. Risk factors and cardiovascular disease in Turkey. Atherosclerosis 2001;156:1-10.

21. Genuth S, Alberti KG, Bennett P, Buse J, Defronzo R, Kahn R, et al. Expert Committee on the diagnosis and classification of diabetes mellitus. Follow-up report on the diagnosis of diabetes mellitus. Diabetes Care 2003; 26:3160-7.

22. Executive Summary of the Third Report of the National Cholesterol Education Program (NCEP). Expert panel on detection, evaluation and treatment of high blood cholesterol in adults (Adult Treatment Panel III). J Am Med Assoc 2001;285:2486-97.

23. Grundy SM, Brewer HB, Cleeman JI, Smith SC, Lenfant C. Definition of metabolic syndrome: report of the National Heart, Lung, and Blood Institute/American Heart Association conference on scientific issues related to definition. Circulation 2004;109:433-8.

24. Onat A, Uyarel H, Hergenç G, Karabulut A, Albayrak S, Can G. Determinants and definition of abdominal obesity as related to risk of diabetes, metabolic syndrome and coronary disease in Turkish men: a prospective cohort study. Atherosclerosis 2007;191:182-90.

25. Rose G, Blackburn H, Gillum RF, Prineas RJ. Cardiovascular survey methods, 2nd ed. Geneva: WHO, 1982:1247.

26. Hanis CL, Hewitt-Emmett D, Douglas TC, Schull WJ. Lipoprotein and apolipoprotein levels among MexicanAmericans in Starr County, Texas. Arterioscl Throm Vas 1991;11:123-9.

27. Assmann G, Schulte H. Results and conclusions of the Prospective Cardiovascular Münster (PROCAM) Study. In: Assmann, editor. Lipid metabolism disorders and coronary heart disease. München: MMV Medizin Verlag, 1989:40.

28. Ribas V, Sanchez-Quesada JL, Anton R, Camacho M, Julve J, Escola-Gil JC, et al. Human apolipoprotein A-II enrichment displaces paraoxonase from HDL and impairs its antioxidant properties: a new mechanism linking HDL protein composition and antiatherogenic potential. Circ Res 2004;95:789-97.

29. Onat A, Hergenç G, Dursunoğlu D, Küçükdurmaz Z, Bulur S, Can G. Relatively high levels of serum adiponectin in obese women, a potential indicator of antiinflammatory dysfunction: relation to sex hormonebinding globulin. Int J Biol Sci 2008;4:208-14.

30. Sauvaget $D$, Chauffeton V, Dugué-Pujol S, Kalopissis AD, Guillet-Deniau I, Foufelle F, et al. In vitro transcriptional induction of the human apolipoprotein A-II gene by glucose. Diabetes 2004;53:672-8.

31. Dodani S. Excess coronary artery disease risk in South Asian immigrants: can dysfunctional high-density lipoprotein explain increased risk? Vasc Health Risk Manage 2008;4:953-61.

32. Brousseau ME, Millar JS, Diffenderfer MR, Nartsupha C, Asztalos BF, Wolfe ML, et al. Effects of cholesterol ester transfer protein inhibition on apolipoprotein (apo) A-IIcontaining HDL subspecies and apo A-II metabolism. J Lipid Res 2009;50:1456-62. 